\title{
Rethinking syntax: A commentary on E. Kako's "Elements of syntax in the systems of three language-trained animals"
}

\author{
IRENE M. PEPPERBERG \\ University of Arizona, Tucson, Arizona
}

\begin{abstract}
Kako (1999) requests new studies of linguistic continua between humans and nonhumans. I question the value of such studies and the importance of determining whether any component of language is uniquely human. I argue that training of specific constructs (e.g., closed classes) may not provide appropriate data, and that whether a particular species lacks or has human-like syntax likely results from specific ecological/evolutionary pressures. Social factors purported to drive intelligence and communication in primates likely exist for nonprimates such as parrots; moreover, Grey parrots demonstrate rudiments of supposedly uniquely human abilities: supralaryngeal vocal tract control, anticipatory coarticulation, and sound play.
\end{abstract}

Kako (1999) is correct in stating that sophisticated language use is often considered the Rubicon that separates human from nonhuman animals (see, e.g., Bickerton, 1990; Pinker, 1994). Debate concerning the linguistic competency of nonhumans reached its greatest stridency with the charges and countercharges published from the late 1970 s to the end of the 1980s (for an example, see the edited volume by Sebeok \& Rosenthal, 1981). The general content was summed up by Fouts (1973), who noted that the definition of language had become essentially whatever animals could not be shown to do. Clearly, some of the original claims for animal linguistic competence lacked sufficient supporting data, and the resulting "shake-up" eventually strengthened rather than weakened the field. But even heavily criticized studies demonstrated that nonhumans could use symbols referentially, could refer to objects in their absence, and could comprehend far more of human language than was ever thought possible. Kako now revives the debate, but more as a challenge to researchers in the field to push their animal subjects to demonstrate additional forms of linguistic competence. I can't help but wonder, however, as to what we would indeed learn if we were to acquire such data. I concentrate on two issues: first, one of Kako's specific training suggestions; second, the general importance of looking at syntactic structure. I close with some additional brief comments.

For simplicity, I focus on Kako's suggestion that I teach a Grey parrot (Psittacus erithacus), Alex, closed classes of in versus on. Interestingly, I proposed such a study in my current grant proposal but have let it slide in favor of

This commentary was prepared under the support of National Science Foundation Grant IBN 96-03803. I thank Spencer K. Lynn, Diana L. May, and Dianne K. Patterson for their input and our many lively discussions on the topic. Correspondence concerning this article should be addressed to I. M. Pepperberg, Ecology and Evolutionary Biology, University of Arizona, Tucson, AZ 85721 (e-mail: impepper@u.arizona. edu). what I feel are more interesting projects. The reasons for my decision are as follows. Given that Alex (and several other Grey parrots and parrot species) have demonstrated what appears to be full object permanence (see, e.g., Funk, 1996; Pepperberg \& Funk, 1990; Pepperberg, Willner, \& Gravitz, 1997), these birds clearly understand the concepts of in versus on: They understand that to obtain a desired item that is in another object, one type of physical manipulation must be used; if the desired item is on another object, the birds' manipulation is very different. Kako suggests that I map English labels onto these already demonstrated concepts. I'm not quite sure what I would gain from such an exercise. According to Kako, Alex et al. would then demonstrate closed classes - a critical element of syntax. In my opinion, and likely in the opinion of many critics, the birds would instead have encoded a spatial relationship - not an entirely trivial bit of learning, but not one specifically syntactical, nor one as interesting as, for example, demonstrating numerical ordinality or an understanding of mass conservation. I am, in fact, more eager to test whether my parrots can encode spatial relationships such as over versus under, which require both objects to be physically in view and involve a reversible relation between them. Moreover, the basic in/on distinction does not exist in some languages (e.g., Spanish), whereas even greater in/on distinctions are made in others (e.g., German; see Bowerman, 1989). Thus, the extent to which a concept is restricted depends on the language chosen and the use to which the subject puts the construct: If we evaluate use of closed-class elements in terms of complexity of communication, we see that responding to queries ("in box" vs. "on box") is not the same as commenting spontaneously about the environment or understanding how to use a construct metaphorically ("in trouble"). I realize that I am pushing Kako's suggestions beyond what he likely intended - I assume he used in/on merely as an example of closed classes, and that any preposition would suffice- but my point is that training a spe- 
cific construct may not have the intended result and, because interpretations of the results will vary significantly, may not provide the linguistic information Kako desires.

As for the general topic of syntax, I feel that using linguistic competence (e.g., syntax) to determine what makes humans unique from nonhumans or to determine what aspects of human language are species specific simply is not a personally interesting topic. It is likely that whether a specific avian species will turn out to lack or have the capacity for human-like syntax will be a consequence of specific ecological and evolutionary pressures; what is lacking in one species may be found in another. Among very closely related species, some birds do seem to have and appear to attend to a rudimentary syntax, whereas others do not; for example, swamp sparrow (Melospiza georgiana) song appears to lack syntax, consisting of one phrase of a trill of one repeated multinote syllable, whereas song sparrow (Melospiza melodia) song has a clear structure of multiple phrases, made of several trills of repeated syllables separated by distinct note complexes (see the review in Searcy, Marler, \& Peters, 1981). The evidence that song sparrows may be sensitive to their elementary song syntax is that they are more likely to learn allospecific syllables if the syllables are presented in the conspecific pattern (Marler \& Peters, 1981).

At first glance, we may decide that song sparrow communication is more complex and advanced-but we know that for other birds with "simple" songs, such as flycatchers, complexity arises not in the song itself but in contextual variation of the song. Eastern wood-pewees (Contopus virens), for example, may use the specific context or relative number of repetitions of a single, simple song type sung by a conspecific to assess how the singer will be likely to act (Smith, 1988, 1991). Do we count these contextual variables as syntactic? What do striking differences between closely related species really tell us? Such data are not even likely to provide information about ancestral lines: For separate populations of white-crowned sparrows (Zonotrichia leucophyrs), for example, similarity in song development is better correlated with annual migratory cycle than with recency of common ancestry (Nelson, Marler, \& Morton, 1996). What, then, do we learn if we find that a particular linguistic trait is or is not restricted to humans?

I also question the importance of determining whether any one component of language is uniquely human. Lieberman (1996) argues that certain aspects of speech are special, but let us see how some behavior patterns that he claims are unique to human language are demonstrated by Alex.

Lieberman (1996) writes:

The voluntary control of the supralaryngeal vocal tract (SVT) for linguistic ends appears to be a unique human characteristic. The neural structures that are implicated in the regulation of the human SVT essentially store and rapidly access automatized patterns of muscular activity that have a linguistic rather than an emotive function. ... The automatized SVT patterns of human speech are largely independent of affect and psychological state. Humans, therefore, can produce sounds that have an arbitrary relationship to their emotional state. The sounds that make up the word help, for example, in themselves do not have any emotional quality. The sound [h] can just as well be used in the word hello. In contrast, the vocal signals of other mammals appear to be tied to their affective state (p. 56).

Alex's vocal identification of colors, shapes, and objects require complex voluntary control of his supralaryngeal vocal tract: Different supralaryngeal vocal tract configurations have been documented for his different vowels and consonants (see Patterson \& Pepperberg, 1994, 1998; Warren, Patterson, \& Pepperberg, 1996). He not only produces "tea" and "pea," however, which require distinct configurations and fine motor control (and does so with clearly distinguishable voice onset times that are comparable to mine), but also understands that one is used to request a sip of a herbal concoction and the other a bite of vegetable; thus, his formulations are digital, not analog. Furthermore, his speech is used in ways that do and do not reflect emotional states. Identifications of colors and shapes, for example, are independent of affective state, whereas it is likely that requests for particular actions (e.g., "tickle," "want showah" [shower]) do have emotional contexts. His use of [t] in both "tickle" and "two-corner" thus seem to parallel Lieberman's statements about a human [h].

Lieberman (1991) also claims that "The production of speech appears to be the most difficult motor control task that humans perform. The instructions that the brain must transmit to the muscles of the tongue and other speech organs have the complexity of the syntactic rules of human language and some aspects of rule-governed logic" (p. 83). He goes on (pp. 83-84) to describe the different forms of anticipatory coarticulation needed to produce "two" [tu] versus "tea" [ti], the former requiring lip rounding for the $[\mathrm{u}]$. He casts this behavior as:

\footnotetext{
Therefore, the rule "reads": round the consonant so that it agrees in rounding with the vowel that follows it. It is not different in form from similar linguistic rules presented by Chomsky and Halle (1968). Rules of this form, coupled with sufficient memory, are sufficient to account for the full complexity of languages such as English (Gazdar, 1981). (p. 84)
}

My graduate student and I provide evidence for apparently similar anticipatory coarticulation in Alex's production of "key" [ki] versus "cork" [kork]: a clear difference in timing for and extent of beak opening during $[\mathrm{k}]$ production depending on the following vowel (Patterson \& Pepperberg, 1998). Does Alex thus have a form of syntax previously thought to be unique to humans? Repp (1986), however, argues that some forms of human anticipatory coarticulation exist because they simply cannot be avoided in the production of certain sound combinations. If we cannot make voluntary/involuntary distinctions in humans, how can we make them in nonhumans? Again, my point is simply that arguing for (and about) linguistically based species differences, and challenging researchers to obtain data to refute or support such differences, may not provide results that are conclusive. 
As an aside, I must comment on one of Kako's examples of Alex's competence and discuss another for which comprehensive published data is lacking. With respect to the first example, Alex did not learn rock as an adjective for hardness; rather he learned it as the label for a lava-stone beak conditioner. Whether he abstracted the concept of hardness from the rock and intentionally applied it to the dried corn to form rock corn or simply hit upon the term in the course of his practice "babbling" will never be known. With respect to the second example, my students and I have found that analyses of tapes of what we call solitary sound play (i.e., practice, when alone in the evening, of material trained during the day; Pepperberg, Brese, \& Harris, 1991) demonstrate that our birds recombine existent labels according to a specific rule: To create novel utterances, they recombine beginnings and ends of existent labels, rather than ends with ends or beginnings with beginnings. Thus we commonly hear utterances such as "banacker" (banana-cracker), but never "bancrack" or "ana-er." The meaning of the use of this rule is unclear, but suggests some sensitivity to internal order and subunit structure that is not necessarily expected in nonhumans.

I close with a note about Kako's point suggesting that argument structure has its roots in mammalian social intelligence. The point is reminiscent of Humphrey's (1976) suggestion concerning the evolution of general intelligence and Rozin's (1976) definition of intelligence as flexibility in transferring skills acquired in one domain to another. How these two patterns might drive parrot cognitive skills and vocal behavior seems obvious: Long-lived birds existing in complex social systems, not unlike those of some primates, use abilities honed for social gains to direct other forms of information processing and vocal learning. Add the need for categorical classes (e.g., to distinguish neutral stimuli from predators, poisonous from healthful foods, etc.), the need to recognize and remember environmental regularities and to adapt to unpredictable environmental changes over an extensive lifetime, and the need to acquire a communication system that is primarily vocal: Parrot cognitive abilities, whether or not syntactically expressed, should match those of nonhuman primates.

Clearly, animal linguistic competence is of interest to some of my colleagues, and I applaud the diversity of our interests. I also appreciate Kako's requests to look for linguistic continua between humans and nonhumans. My personal research goals, however, are to examine cognitive similarities and differences and to determine what, if any, continua exist in cognitive and information processing abilities across and between species. I thus see syntactic capacity as only one aspect of cognition and, to my mind, one that is too fraught with alternative interpretations to be of interest in my research.

\section{REFERENCES}

BiCKERTON, D. (1990), Language and species. Chicago: University of Chicago Press.
Bowerman, M. (1989). Learning a semantic system: What role do cognitive predispositions play? In M. L. Rice \& R. L. Schiefelbusch (Eds.), The teachability of language (pp. 133-169). Baltimore: Brookes.

Fouts, R. (1973). Capacities for language in the great apes. In S. Tax \& G. C. Neuberger (Eds.), Proceedings of the Ninth International Congress of Anthropological and Ethnological Sciences. The Hague: Mouton.

FUNK, M. S. (1996). Development of object permanence in the New Zealand parakeet (Cyanoramphus auriceps). Animal Learning \& Behavior, 24, 375-383.

Humphrey, N. K. (1976), The social function of intellect. In P. P. G. Bateson \& R. A. Hinde (Eds.), Growing points in ethology (pp. 303317). Cambridge: Cambridge University Press.

KAKO, E. (1999). Elements of syntax in the systems of three languagetrained animals. Animal Learning \& Behavior, 27, 1-14.

Lieberman, P. (1991). Uniquely human. Cambridge, MA: Harvard University Press.

Lieberman, P. (1996). Some biological constraints on the analysis of prosody. In J. L. Morgan \& K. Demuth (Eds.), Signal to syntax: Bootstrapping from speech to grammar in early acquisition (pp. 55-65). Hillsdale, NJ: Erlbaum.

MARLER, P., \& PETERS, S. (1981). Birdsong and speech: Evidence for special processing. In P. Eimas \& J. Miller (Eds.), Perspectives on the study of speech (pp. 75-112). Hillsdale, NJ: Erlbaum.

Nelson, D. A., MARLer, P., \& MorTON, M. L. (1996). Overproduction in song development: An evolutionary correlate with migration. $A n$ imal Behaviour, 51, 1127-1140.

Patterson, D. K., \& Pepperberg, I. M. (1994). A comparative study of human and parrot phonation: Acoustic and articulatory correlates of vowels. Journal of the Acoustical Society of America, 96, 634-648.

Patterson, D. K., \& Pepperberg, I. M. (1998). Acoustic and articulatory correlates of stop consonants in a parrot and human subject. Journal of the Acoustical Society of America, 103, 2197-2215.

Pepperberg, I. M., Brese, K. J., \& Harris, B. J. (1991). Solitary sound play during acquisition of English vocalizations by an African Grey parrot (Psittacus erithacus): Possible parallels with children's monologue speech. Applied Psycholinguistics, 12, 151-178.

PEPPERBERG, I. M., \& FUNK, M. S. (1990). Object permanence in four species of psittacine birds: An African Grey parrot (Psittacus erithacus), an Illiger mini macaw (Ara maracana), a parakeet (Melopsittacus undulatus), and a cockatiel (Nymphicius hollandicus). Animal Learning \& Behavior, 18, 97-108.

Pepperberg, I. M., Willner, M. R., \& Gravitz, L. B. (1997). Development of Piagetian object permanence in a Grey parrot (Psittacus erithacus). Journal of Comparative Psychology, 111, 63-75.

PINKER, S. (1994). The language instinct: How the mind creates language. New York: Morrow.

REPP, B. H. (1986). Some observations on the development of anticipatory coarticulation. Journal of the Acoustical Society of America, 79, 1616-1619.

Rozin, P. (1976). The evolution of intelligence and access to the cognitive unconscious. In J. M. Sprague \& A. N. Epstein (Eds.), Progress in psychobiology and physiological psychology (Vol. 6, pp. 245-280). New York: Academic Press.

Searcy, W. A., Marler, P., \& Peters, S. S. (1981). Species song discrimination in adult female song and swamp sparrows. Animal Behaviour, 29, 997-1003.

Sebeok, T. A., \& Rosenthal, R. (EDs.). (1981). The Clever Hans phenomenon: Communication with horses, whales, apes, and people (Annals of the New York Academy of Sciences, Vol. 364 ). New York: New York Academy of Sciences.

SмIтн, W. J. (1988). Patterned daytime singing of the eastern woodpewee (Contopus virens). Animal Behaviour, 36, 1111-1123.

SмITH, W. J. (1991). Animal communication and the study of cognition. In C. A. Ristau (Ed.), Cognitive ethology: The minds of other animals (pp. 209-230). Hillsdale, NJ: Erlbaum.

Warren, D. K., Patterson, D. K., \& Pepperberg, I. M. (1996). Mechanisms of American English vowel production in a Grey parrot. Auk, $113,41-58$ 